\title{
HART: ALGUNOS PUNTOS CRÍTICOS
}

\section{El problema epistemológico}

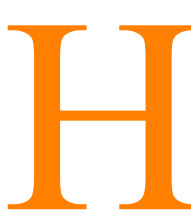

art es un autor con escaso sentido epistemológico. En vano se buscaría en su obra una respuesta, y ni siquiera una pregunta, sobre lo que sea la ciencia jurídica o la teoría general del derecho, o sobre cuáles son los límites que existen entre ellas y la filosofía del derecho. La obra de Hart se caracteriza, a este respecto, por presentar un sorprendente mutismo. En su The Concept of Law lo más que encontramos es una lacónica afirmación en el Prólogo, según la cual el jurista mirará el libro como un «ensayo de jurisprudencia analítica, habida cuenta de que se centra en la clarificación del marco general del pensamiento jurídico, más que de crítica al derecho o política jurídica». Y en el párrafo siguiente, volviendo sobre el carácter que hay que adscribir al libro, nos dice: «dejando de lado el que el libro esté centrado en el análisis, el libro puede ser considerado también como un ensayo de sociología descriptiva».

«El Concepto de Derecho» es, pues, según las propias palabras de su autor, una obra de jurisprudencia analítica y de sociología descriptiva al mismo tiempo. No es que se proponga primero una cosa y después la otra, sino que posee, y las posee conscientemente, las dos dimensiones. Lo que en Kelsen constituía uno de los objetivos máximos de preocupación epistemológica (el evitar el sincretismo metódico, y especialmente separar la ciencia jurídica de la sociología del derecho), en Hart pasa a ser objetivo a alcanzar. Está en su derecho el proponérselo así, puesto que todo autor determina el marco de su investigación. Pero ello a condición de que razone por qué adopta tal decisión metodológica. Hart nos indica cuál es el carácter de su obra, pero no da ni un solo argumento que justifique su declaración. Esta carencia de sentido epistemológico es injustificable en cualquier teórico que intente seriamente la construcción fundamentada de una teoría. Por este motivo, podemos afirmar que ya desde el prólogo de su obra, ésta carece de 
uno de los elementos fundamentales de toda construcción teórica del derecho: la justificación del punto de vista adoptado. Sin tal justificación explícita el teórico del derecho condena de antemano su obra a un futuro estéril, por muy sugerentes que sean sus propuestas. Se habrá quedado a mitad de camino, e incluso podría decirse que ni siquiera lo ha empezado de verdad.

La verdad de las palabras de Hart de que su obra constituye tanto un ensayo de jurisprudencia analítica (o teoría general del derecho) como de sociología descriptiva, se ven confirmadas a lo largo de las páginas de su obra, en las cuales se alterna sin orden el tratamiento característico de la teoría general (análisis eminentemente formal de la estructura de las reglas jurídicas y de los conceptos jurídicos) con el propio de las observaciones sociológicas (referencias continuas a la realidad social). Pero la mixtificación no acaba aquí. En efecto, a Hart se le ha olvidado decir en el Prólogo que el libro también puede ser considerado como un ensayo de derecho natural, aunque sea de derecho natural «mínimo», pues junto al estudio característico de la teoría general del derecho y de la sociología descriptiva, encontramos también la declaración (y el correspondiente desarrollo) de que es preciso reconocer un derecho natural mínimo, es decir un conjunto de valores jurídicos mínimos que necesariamente aparecen como implicados en la mera existencia del derecho como orden de la convivencia social. Habría, por tanto, que reformular su autopercepción y decir que «El Concepto de Derecho» es un libro tanto de jurisprudencia analítica (o teoría general del derecho), como de sociología descriptiva, así como, también de derecho natural mínimo. De esta manera, consuma Hart lo que podemos llamar la mixtificación tridimensionalista, ya que en su obra aparecen los tres elementos mezclados en una especie de concepción «cóctel» del derecho: la norma o regla (que será el objeto básico de la jurisprudencia analítica), el hecho social (centro de interés de la sociología descriptiva) y el valor mínimo que todo derecho encarna por el mero hecho de existir como sistema de reglas regulador de la conducta humana (expresión de lo que el propio Hart llama derecho natural mínimo, situándose en ello como fiel discípulo de Hobbes). La carencia de conciencia epistemológica le ha llevado a Hart a esta mixtificación extrema, cuyo resultado último es la confusión conceptual, la mezcla disciplinar y, en definitiva, la pérdida del valor científico del conocimiento jurídico.

Ahora bien, a pesar de que Hart incorpore en su teoría los tres elementos señalados en una mezcla algo confusa, podemos situar su obra, como es usual, en la línea de la jurisprudencia analítica inglesa y, por tanto, considerarla como una expresión de lo que en el continente se ha denominado teoría general del derecho. Primero, porque se muestra a sí mismo como un representante del positivismo jurídico. Pero, además, porque su pensamien- 
to hay que entenderlo en conexión con los representantes clásicos de la teoría analítica: Hobbes, Bentham y Austin, por una parte, y Kelsen por otra. Su centro de interés lo constituye el derecho positivo y su objetivo consiste, como él mismo señala, en clarificar «la estructura general del pensamiento jurídico», o más certeramente, la estructura del derecho en general. Cuando habla de derecho natural mínimo lo vincula al concepto mismo de derecho positivo, resaltando que no se trata de un conjunto de principios de carácter apriorístico a partir de los cuales se obtendrían por deducción los preceptos de derecho natural, sino más bien de las ideas de valor (especialmente seguridad y adopción de reglas generales) que se encuentran ínsitas en la misma existencia del derecho. El elemento sociológico juega también su papel, aunque no relevante, de tal manera que no parece muy adecuado calificar su obra como un ensayo de sociología jurídica. El hecho de que Hart así la califique constituye más una exageración de un autor que ve con muy buenos ojos su propia obra, que un juicio desapasionado de lo que ésta representa. Que en su obra «El Concepto de derecho» aparezcan elementos de carácter sociológico es una buena prueba de su mixtificación metódica. También aparecen esos elementos en las obras de Kelsen y de Ross y, sin embargo, a estos autores no se les ocurre decir que aquellas puedan ser consideradas como ensayos de «sociología descriptiva». Hart es heredero de la tradición de la analytical jurisprudence, que se basa en la separación entre el derecho que es y el derecho que debe ser, y en la contraposición, paralela a la anterior, entre jurisprudencia descriptiva o expositiva y jurisprudencia crítica o censoria. Tal es la terminología empleada por Bentham, quien con el término expository jurisprudence se refiere a la jurisprudencia o ciencia del derecho que se limita a exponer o describir su objeto, que es el derecho positivo o puesto por los seres humanos, y con el de censorial jurisprudence alude a la crítica del derecho, a la investigación del derecho que debe ser, o en otras palabras, al arte de la legislación (art of legislation) ${ }^{1}$. Esta contraposición es introducida asimismo por Austin, aunque con distinta terminología. Austin distingue entre General jurisprudence (a la cual denomina también Philosophy of positive law) y ethics (que corresponde a lo que Bentham denomina deontology), indicando con el primer término la ciencia del derecho que tiene por objeto el estudio del derecho positivo, y con el segundo la crítica del derecho a partir de unos determinados valores que se dan por buenos, y cuyo lugar adecuado en relación con el derecho es

${ }^{1} \mathrm{~J}$. Bentham, The Principle of Morals and Legislation, Prometheus Books, Buffalo, New York 1988, p. 324. 
lo que Austin denomina ciencia de la legislación (science of legislation)2. Esa misma distinción es acogida por Hart en las frases del Prólogo que comentamos, y según las cuales, como hemos visto, hay que considerar su obra como un ensayo de jurisprudencia analítica, y no de «crítica del derecho o política jurídica», que sería la equivalente a la jurisprudencia censoria y a la ciencia de la legislación, como expresión de la ética o deontología.

Es el mismo Hart el que adopta como punto de partida y de referencia constante la obra de John Austin, al que estereotipa en lo que él llama el «modelo simple» de la teoría general del derecho, para, a partir de su crítica (centrada sobre todo en la crítica al imperativismo y al modelo simple de las reglas), construir su propia teoría. Pero sería miope creer que la intelección del pensamiento hartiano haya de hacerse tan sólo desde la perspectiva de su conexión con el pensamiento jurídico inglés, y más en concreto con Austin. La teoría analítica del derecho no es exclusiva del positivismo jurídico inglés; antes bien, tiene también un profundo desarrollo en el continente europeo. No en vano Austin bebió en las fuentes de la filosofía Jurídica alemana del positivismo, inspirándose muy fuertemente en ellas para la elaboración de su capital obra Lectures on Jurisprudence ${ }^{3}$. A través de la obra de Austin penetra en Inglaterra el análisis conceptual de los representantes de la escuela histórica alemana (Savigny, Hugo) y de sus herederos los conceptualistas, que ven culminado sus esfuerzos en la creación de la allgemeine Rechtslehre. En el siglo XX, autores como Bierling, Somlò y Kelsen representan importantes cimas del pensamiento analítico en el campo del derecho. Es este último quien, por las especiales vicisitudes de su vida y por sintetizar mejor que nadie el esquema fundamental de la teoría general del derecho- llegaría a ser conocido en los países de habla inglesa. En este sentido, la aparición de la obra de Kelsen General Theory of Law and State, en el año 1945, constituye un hito decisivo. Las dos raíces fundamentales a partir de las cuales hay que entender e interpretar la obra hartiana son, pues, el pensamiento austiniano y el kelseniano, si bien de éste último no en su extensa evolución sino en referencia a la obra publicada en inglés, especialmente la mencionada.

Cuestión distinta es la del trasfondo de filosofía general del pensamiento de Hart. En el Prólogo de su obra principal cita a J. I. Austin, el filósofo del lenguaje, autor de How to do things with words (Cómo hacer cosas con

${ }^{2}$ J. Austin, Lectures on Jurisprudence or The Philosophy of Positive Law, 5.ed. revisada y ed. Por Robert Campbell, London 1885 (reimpr. Verlag D. Auvermann KG/ Glashütten im Taunus, Darmstadt 1972), p. 32. ${ }^{3}$ Cfr. Ardunio Agnelli, John Austin alle origini del positivismo giuridico, Giappichelli,
Torino 1959. ${ }^{3}$ Cfr. Ardunio Agnelli, John Austin alle origini del positivismo giuridico, Giappichelli,
Torino 1959. 
palabras $)^{4}$. Austin sigue la concepción de la filosofía del lenguaje característica del llamado segundo Wittgenstein, quien centra el hacer filosófico en el análisis del lenguaje ordinario (a diferencia del primer Wittgenstein, cuyo centro de interés radicaba en el análisis del lenguaje científico o formalizado). Más en concreto, la preocupación de Austin, siguiendo a Wittgenstein, es el estudio de los usos del lenguaje; de ahí el título de su conocida obra: al emitir palabras no sólo decimos cosas, sino que también «hacemos cosas» (por ejemplo, insultamos, alabamos, censuramos, describimos, etc.). Sería quizá más apropiado decir que al emitir palabras realizamos acciones, con lo cual la teoría del lenguaje estaría íntimamente conectada con la teoría de la acción.

Pues bien, a lo que vamos es a que se suele ver en esta filosofía del lenguaje ordinario el soporte filosófico de la concepción jurídica de Hart. Éste habría tratado de elaborar su concepción aplicando al estudio del derecho los modos de operar de la filosofía analítica del segundo Wittgenstein y de Austin. Incluso algún autor ha llegado a decir que Hart no manifiesta suficientemente de manera expresa el influjo recibido por Wittgenstein, influjo que habría ocultado celosamente ${ }^{5}$. Síntomas de esta actitud de seguimiento de la filosofía del lenguaje ordinario serían la actitud crítica de Hart hacia el modo tradicional de definir (basado en la diferenciación entre género próximo y diferencia especifica), su tesis de la porosidad de los conceptos jurídicos (que sería una consecuencia de la porosidad del propio lenguaje) y su escapismo a la hora de enfrentarse ante el concepto del derecho. Por nuestra parte, creemos que no hay que exagerar el influjo de la filosofía del lenguaje en la obra de Hart. Mucho menos el que fuera un profundo conocedor de Wittgenstein. Por el contrario, nos parece que sus principales tesis son el producto de la continuación y la crítica del pensamiento jurídico positivista, sobre todo de Bentham, Austin y Kelsen. Así, por ejemplo, cuando critica la concepción tradicional del modo de definir (genus proximum, differentia specifica) dice seguir en ello los pasos de Bentham, quien ya advertía de la necesidad de entender las palabras no aisladamente consideradas, sino en el contexto de las diferentes frases en que son usadas. No hay que atender, por ejemplo, a la palabra right, desvinculada de su contexto, sino a la frase you have a right; no tiene sentido definir la palabra state, desligada de todo contexto, sino que habrá que entender su significado en la

${ }^{4}$ Hay que llamar la atención sobre el hecho de la coincidencia de nombres entre el Austin jurista, del siglo pasado, y el Austin filósofo. Éste último nació en 1911 y murió en 1960. Fue profesor de filosofía moral en Oxford. La obra citada en el texto aparecería póstumamente en 1962. 1969.

${ }^{5}$ Tal es el parecer de Eckmann, Rechpositivismus und sprachanalystiche Philosophie, Berlin 
frase «he is a member or an official of the state». Estos son ejemplos de Bentham que Hart hace suyos para seguir su doctrina ${ }^{6}$. En lugar de definir los conceptos, Hart propone el método de «elucidar» (method of elucidation) ${ }^{7}$, lo que viene a significar: explicar o aclarar el concepto de que se trate, para lo cual nada mejor que entender el concepto en el contexto de la frase donde aparece. Tal, dice el propio Hart, es el método que Bentham practicó. Partiendo de estas ideas es fácil comprender lo que Hart quiere decir con «porosidad» de los conceptos: los contornos de éstos no estarían claramente delimitados de una vez por todas sino que estarían dotados de la ambigüedad permanente que ostenta en lenguaje ordinario, que además está sometido a un cambio continuo.

Estas ideas subyacen a toda la obra de Hart y especialmente a su The Concept of Law, en la que, a pesar del título, en vano se buscará un «concepto» del derecho entendido al modo de lo que Hart llamara tradicional. La clave la encontramos en el último capítulo (dedicado al derecho internacional), en el cual Hart nos aclara que el propósito del libro es ofrecer «an elucidation of the concept of law, rather than a definition of law» ${ }^{8}$. Lo que se propone Hart en su libro no es dar una definición del derecho, sino aclarar o explicar el concepto del mismo. Ahora bien, ¿una aclaración e «elucidación» suficiente del concepto de derecho no es en sí misma la definición del mismo? ¿Por qué pensar que el modo «tradicional» de definir mediante género y diferencia específica está en contradicción con el análisis del uso de las palabras? ¿Acaso si definimos el derecho determinando su género p.ej., «sistema de normas» -y su diferencia- «dotado de las características tales y cuales que las diferencian de otras normas», estaremos haciendo algo que esté en radical contraposición con lo que significa «elucidar» un concepto? ¿No será que Hart huye del compromiso de las definiciones para situarse en la cómoda posición que le otorga la «porosidad» del lenguaje?

El planteamiento que Hart hace de este problema está en la línea marcada por un importante trabajo de Glanville Williams, titulado «The Controversy Conceming the Word 'Law'»'. Este autor arremete contra la idea de Austin de que el significado «propio» del derecho sea el derecho estatal, ne-

${ }^{6}$ Cfr. Hart, «Definition and Theory in Jurisprudence», Law Quarterly Review, vol. 70 (En. 1954), ahora en H.L.A. Hart, Essays in Jurisprudence and Philosophy, Clarendon Press, Oxford 1983 (pp. 21-48), p. 26.

${ }^{7}$ Ibid. p. 33.

${ }^{8}$ The Concept of Law, p. 208.

${ }^{9}$ Publicado en The British Yearbook of International Law, 1945, y después en Philosophy, Politics and Society, a cargo de Peter Laslett (Blackbell, Oxford 1956, pp. 136-156); hay trad. Italiana a cargo de Mario Jori, «La controversia a proposito della parola "Diritto"», en Diritto $e$ analisi del linguagio, a cura di Uberto Scarpelli, Edizioni di Comunità, Milano 1976, pp. 43-72. 
gando así carácter jurídico al derecho internacional, que vendría a ser un aspecto de la moral. Williams protesta por esta reducción injustificada afirmando que Austin no ha entendido lo que significa el uso de las palabras. «La palabra "derecho" es simplemente un símbolo de una idea. Esta idea puede variar según la persona que use la palabra. Austin define lo que la palabra significa para él, cosa que tiene el derecho de hacer; pero no tiene derecho alguno de asumir una posición de legislador y declarar lo que la palabra debe significar para los demás». No existe para Williams un significado «propio» de las palabras, sino todo lo más un significado «usual» ${ }^{10}$. El método que propone este autor es «estudiar el significado ordinario de las palabras» renunciando a las definiciones «verdaderas» y a los significados «propios». Señala que este método debe ser característico tanto de la filosofía como de la jurisprudencia analítica, que «deben partir de las palabras tal y como son realmente usadas» siendo inútil «producir definiciones a priori declarando a continuación que son "verdaderas" o "propias" ${ }^{11}$. No hace falta, pues, remontarse a la influencia de Wittgenstein para entender que Hart diga en su Prólogo que en el libro se plantea «cuestiones que bien puede decirse que versan sobre el significado de palabras»».

De semejante naturaleza al estudio de Willips es otro de Richard Wollheim titulado «The Nature of $L a w »{ }^{12}$, en el que polemizando nuevamente con Austin, llama la atención sobre la necesidad de considerar como una cuestión sobre el significado de las palabras preguntas tales como: «¿cuál es la naturaleza del derecho? o ¿cuál es la esencia del derecho?» Wollheim responde que a tales «cuestiones lingüísticas» se puede responder de tres modos: proporcionando una «definición explícita o equipolente» (que es lo que se suele denominar definición nominal: el definiendum expresa en una palabra un conjunto de palabras, que es el definiens), o bien una definición de uso (en la que la palabra en cuestión aparece en distintos discursos de lenguaje), o bien, por último, una elucidación (elucidation) o explicación del concepto, que no es sino «una caracterización general» de lo que el término en cuestión significa. Salta a la vista que la dilucidación o explicación de un concepto es la forma más laxa de aproximarse al término que se trata de explicar (en nuestro caso, el término «derecho»).

\section{Punto de vista interno y punto de vista externo}

Otro de los aspectos de la perspectiva epistemológica de la obra hartiana es la idea de que el derecho puede ser contemplado desde el punto de vis-

${ }^{10}$ Ibid. p. 46.

${ }^{11}$ Ibid. p. 66.

${ }^{12}$ Publicado en Political Studies, 2, 1954, pp. 128-141; trad. It. de Letizia Gianformaggio: «La natura del Diritto», Diritto e analisi del linguagio, cit. pp. 73-93. 
ta interno y desde el punto de vista externo. El primero es, el punto de vista del participante, mientras que el segundo es el punto de vista del observador. El participante considera las reglas del derecho como algo a lo que está sometido. Las reglas le obligan. Por el contrario, el observador externo las contempla como una realidad que no le afecta, ya que está situado fuera de ella. Si utilizamos el símil del juego, diremos que adoptan el punto de vista interno tanto los jugadores como el árbitro, que son los verdaderos sujetos del juego; y el punto de vista externo es el propio de los espectadores, los cuales no participan en la acción de juego $y$, consiguientemente, no están obligados a obedecer las reglas del juego, sino que contemplan éste como algo que sucede, como un fenómeno en el que no participan. A cada uno de estos puntos de vista corresponden enunciados distintos: enunciados internos son aquellos que se producen adoptando el punto de vista interno (esto es, como obligado o destinatario de la norma), mientras que enunciados externos son los que se producen en el marco del punto de vista externo (como observador exterior al fenómeno de las normas).

Se ha dicho que esta distinción corresponde a la diferenciación entre ciencia normativa y sociología del derecho. El punto de vista interno correspondería al jurista, y el externo al sociólogo. El primero en cuanto que considera al derecho como un conjunto de normas obligatorias, se situaría desde dentro del derecho en una posición de acatamiento u observancia. Por el contrario, el sociólogo, al mantener una postura de observador de lo que pasa en su contorno social, se situaría fuera del derecho, con la finalidad de observar los hechos sociales y los comportamientos que tienen que ver con las normas jurídicas.

Aunque el paralelismo tiene mucho de verdad, nos parece que la diferenciación entre punto de vista interno y externo no encaja exactamente con la distinción entre ciencia jurídica y sociología del derecho, y eso porque es una distinción no estrictamente epistemológica o metodológica sino «situacional» en el sentido más puramente natural de este término. El punto de vista interno es el propio de los que ven al derecho desde dentro, y el externo el propio de los que lo contemplan desde fuera. Desde dentro no sólo lo contempla el jurista, sino el ciudadano, y además esa contemplación no tiene por qué ser siempre «normativa» (que es la propia de la ciencia jurídica), sino que también es posible que sea «factualista» (por ejemplo, al considerar el derecho y el estado que se me imponen por la fuerza a mi vida, mi conciencia psicológica puede percibir las normas complacientemente o con desagrado); el punto de vista interno no excluye una perspectiva no normativista. A su vez, desde fuera podemos contemplar el derecho no sólo como un conjunto de fenómenos sociales sino también como un sistema normativo. Así, el estudio del derecho romano lo realizamos como un estu- 
dio de normas jurídicas adoptando el punto de vista de la ciencia normativa, pero no por ello adoptamos un punto de vista interno en el sentido de que nos vemos como «partícipes» del sistema jurídico que examinamos. Parece, pues, que la distinción hartiana es una mezcla algo confusa entre planteamientos epistemológicos y posicionamientos de situación real ante el sistema jurídico. En todo caso, es una distinción que Hart no aclara suficientemente, aunque la utiliza con cierta frecuencia. Nuevamente es como si este autor resolviera sus exposiciones dejando en la sombra de la duda nociones que él mismo considera claves.

\section{Formalismo y escepticismo ante las reglas}

Esa misma ambigüedad (¿buscada?) preside su posición ante las reglas jurídicas. Para ello, Hart divide el mundo de las concepciones jurídicas en dos, que denomina formalistas y escépticas. El formalismo consistiría en una exagerada confianza en la regla escrita, sobre todo en la ley, de manera que la decisión derivaría de ella, sin problema alguno, como un ejercicio mecánico. Hart identifica formalismo con conceptualismo y con «literalismo» (literalism), haciendo así un nuevo ejercicio de inmoderada simplificación. Para entendemos, lo que Hart denomina formalismo sería lo equivalente a la concepción legalista del derecho, según la cual el derecho se identificaría con la ley, y la decisión judicial sería una derivación mecánica (silogística) a partir de ella. La simplificación de lo que Hart denomina «formalismo» alcanza casi el nivel de lo caricaturesco. Para empezar, no tiene en cuenta que donde la palabra «formalismo» tiene su sede natural es en el terreno de las posiciones epistemológicas de la ciencia, y muy secundariamente en el campo de la aplicación del derecho. «Formalismo» es, antes que nada, la actitud metódica que insiste en la investigación de las formas jurídicas como objeto principal de la ciencia jurídica y, más en concreto, de la teoría general del derecho (sin excluir, por ello, la sociología formal). En este sentido la ciencia del derecho será siempre formalista $\mathrm{y}$, por tanto, conceptualista, puesto que uno de sus objetivos es entender la estructura formal del derecho y presentar su descripción en un abanico de conceptos formales que expresen los elementos de aquella estructura y sus relaciones recíprocas. Además, las posiciones formalistas (por ejemplo, teoría pura del derecho o jurisprudencia de conceptos) no conciben la interpretación y aplicación de la ley como Hart dice que las conciben. La presentación que Hart hace resulta francamente decepcionante. El ejemplo que pone es el de la interpretación de la palabra «vehículo», que aparece en la ley y que es preciso determinar para aplicarla al caso concreto. Esta palabra -dice Hart- no presenta problemas de interpretación en el caso de los casos paradigmáticos o casos claros (el coche, el autobús, la motocicleta), pero ¿qué diremos de un coche 
de juguete de propulsión eléctrica? ¿lo consideraremos también un vehículo en el sentido de la ley, y por tanto habrá que entenderse prohibida su circulación en los parques, ya que la ley prohíbe que los «vehículos» circulen por los parques? ${ }^{13}$. Todo el problema del formalismo se reduce, en definitiva, a no haber entendido que el lenguaje tiene una «textura abierta» (open texture), y que por tanto ¡es precisa la interpretación de las palabras en los procesos de aplicación de la ley! La jurisprudencia de conceptos y el formalismo jurídico neokantiano y positivista quedan así definitivamente arrumbados ante el gran argumento del cochecito de juguete... Si no fuera por la extensión y la importancia del libro de Hart, no sería preciso llamar la atención sobre estos temas de una forma tan contundente. Pero, por las características mencionadas, resulta casi obligado dejar bien patente la limitación de los argumentos esgrimidos por Hart en un punto tan importante para entender el pensamiento jurídico como es el formalismo.

Dice Hart: «El vicio conocido en la teoría jurídica como formalismo o conceptualismo consiste en una actitud ante las reglas formuladas verbalmente que pretende dos cosas, disfrazar y minimizar la necesidad de semejante elección (se refiere a la elección de un significado a la hora de interpretar la regla general para ser aplicada al caso concreto), una vez que haya sido establecida una regla general. Una manera de hacer esto es congelar el significado de la regla de tal modo que sus términos genéricos hayan de tener el mismo significado en todos los casos en que se plantee la cuestión de su aplicación ${ }^{14}$. Parece evidente que lo que Hart denomina formalismo (formalism) y conceptualismo (conceptualism) nada tiene que ver ni con las posiciones que tradicionalmente se entienden como representativas del formalismo jurídico ni de la jurisprudencia de conceptos. Más bien tienen que ver con la versión más dura y simplificada de la teoría de la interpretación del derecho mantenida por la Escuela de la Exégesis francesa, sustentada por el dogma de la codificación como expresión de la voluntad general y del derecho natural: si todo está en el código, el intérprete tan sólo tendrá que aplicar mecánicamente la ley (el juez es la bouche de la loi, en palabras de Montesquieu). Esta concepción un tanto ingenua del proceso de aplicación de la ley tan sólo fue sustentada por algunos representantes de la mencionada Escuela francesa, pero no por el formalismo filosófico o científico (de origen kantiano, fenomenológico, o neopositivista) ni por la jurisprudencia de conceptos. Sostener lo contrario implica una ignorancia alarmante tanto de lo que ha representado y representa el formalismo en

\footnotetext{
${ }^{13}$ Cfr. The Concept of Law, cit. p. 125 y s.

${ }^{14}$ Ibid. p. 127.
} 
el pensamiento jurídico como del verdadero alcance de la jurisprudencia de conceptos.

En otro momento al «formalismo» le llama Hart «literalismo» (literalism), palabra ésta que expresa mucho mejor lo que en realidad quiere decir: literalismo es la postura que en verdad critica, que supondría partir de la ingenua idea de que en la literalidad de la ley, en su letra, se encuentra contenido todo el derecho, sin precisar de un ajustamiento al caso concreto mediante una interpretación creadora. Pero por este camino volvemos a nuestra crítica de antes: no es lícito equiparar formalismo y literalismo; no tendríamos nada que objetar si Hart restringiera su crítica al literalismo pero es absolutamente distorsionador extenderla al formalismo, sobre la base de la pretendida equivalencia de ambos. Frente al literalismo, y en ello tiene razón Hart, es preciso subrayar la textura abierta del derecho.

La otra cara de la realidad jurídica es lo que Hart denomina «escepticismo ante las reglas» (rule-scepticism). En su forma más extrema, el escepticismo ante las reglas se manifiesta, para Hart, en la actitud consistente en decir que «hablar de reglas es un mito», olvidando que el derecho «consiste simplemente en las decisiones de los tribunales y en la predicción de las mismas» ${ }^{15}$. Ésta es, la posición de algunos de los más destacados representantes del realismo jurídico americano, para los cuales el derecho no es sino un conjunto de decisiones o sentencias de los jueces, y la ciencia del derecho tiene por objetivo la predicción de cómo decidirán efectivamente los jueces. Hart considera errónea esta concepción extrema, aduciendo que para que haya tribunales que emitan sentencias tiene que haber necesariamente reglas jurídicas que establezcan dichos tribunales, pues en caso contrario «no habría nada que hiciera posible distinguir la decisión de una persona privada de la de un tribunal». Para que existan tribunales tiene que haber reglas de derecho que los instauren; en consecuencia, las reglas están siempre presentes en el derecho, no es posible prescindir de ellas.

La versión moderada del escepticismo ante las reglas acepta la existencia de éstas, pero señala que las leyes no son sino «fuentes del derecho» y no el derecho mismo, que sólo aparece cuando se concretan las leyes mediante las decisiones judiciales. Pero esta objeción, de nuevo, tampoco implica la negación de las reglas que instauran la existencia y constitución de los tribunales, sin los cuales no es posible la emisión de sentencias. Además, aparte de este argumento, que hace referencia a lo que Hart llama «reglas secundarias», no puede desconocerse -añade- que en lo que respecta a las «reglas primarias» (que son las que imponen obligaciones o deberes), éstas funcionan en la vida de los individuos como «accepted legal standards of

${ }^{15}$ Ibid. p. 133. 
behaviour» pautas jurídicas de conducta que aceptan como obligatorias ${ }^{16}$. Frente al predictivismo (que sostiene la idea de que las reglas del derecho no son otra cosa que predicciones sobre lo que harán los tribunales), Hart sostiene que las reglas funcionan en la vida social como tales reglas, son «usadas como reglas y no como descripciones de hábitos o predicciones ${ }^{17}$. Además, los propios jueces no consideran a las reglas jurídicas como predicciones de sus decisiones sino como pautas a seguir en ellas ${ }^{18}$. Esas pautas no excluyen la discreción Judicial, esto es, la libertad de interpretación de los jueces, pero sí la limitan, a veces de una manera considerable. Por todo ello es preciso combinar la existencia de las reglas con la textura abierta de las mismas, para entender así la función judicial, la cual se caracteriza tanto por la discreción como por el sometimiento a las reglas.

\section{Reglas primarias y reglas secundarias}

Llegamos así al punto central de la teoría jurídica de Hart, su aportación decisiva: la distinción entre reglas primarias y reglas secundarias. Una vez que se ha dejado bien claro, frente al rule-scepticism, que no es posible entender cabalmente el derecho si se prescinde de las reglas, preciso es cuestionarse cómo son éstas y cómo se relacionan. Hart toma aquí posición frente a Austin (tal es su método expositivo favorito). O mejor sería decir, frente a lo que llama «modelo simple» de la teoría jurídica, un género de teoría que Austin representa mejor que cualquier otro autor y que ha ejercido y ejerce un poderoso influjo en lo que puede llamarse la mentalidad jurídica corriente.

Hart declara, en efecto, que su principal interés «no está en Austin sino en las credenciales de un cierto tipo de teoría que ejerce una atracción permanente cualesquiera que puedan ser sus defectos. De tal modo que no hemos dudado en ignorar el pensamiento de Austin cuando se manifestaba dudoso o cuando parecía inconsistente, determinando una concepción clara y consistente. Es más, allí donde Austin meramente sugiere pistas para responder a las críticas que se le puedan formular, hemos desarrollado estas pistas (en parte apoyándonos en las líneas seguidas por teóricos posteriores como Kelsen) con el fin de tener la seguridad de que la doctrina que consideramos y criticamos se presenta en su forma más fuerte o rigurosa $\rangle^{19}$. Por tanto, lo que hace Hart para plantear su propia teoría es considerar un «modelo simple» centrado en Austin, aunque «reconstruido» evitando las con-

\footnotetext{
${ }^{16}$ Ibid. p. 134.

${ }^{17}$ Ibid. p. 134. y s.

${ }^{18}$ Ibid. p. 143.

${ }^{19}$ Ibid. p. 18.
} 
tradicciones que aparezcan en Austin y desarrollando la concepción de éste en la línea de otros teóricos, especialmente de Kelsen. De esta forma, Hart sugiere que no sólo está criticando a Austin sino también a Kelsen, aunque la manera de decirlo, según su característica ambigüedad, no sea la más apropiada para un libro científico. El «modelo simple» sería entonces el modelo Austin-Kelsen. Sin decirlo expresamente, que es como hay que decir las cosas, Hart realiza una doble operación respecto a Kelsen: primera, califica su teoría de «simple»; y segunda, presenta a Kelsen como un «seguidor» de Austin.

Esta presentación de Kelsen es más que discutible. Hasta qué punto se pueda considerar a Kelsen como seguidor de la teoría austiniana, es un tema que pasaremos aquí por alto. De cualquier forma también Hart tendría que ser considerado como un seguidor de Austin. Lo que realmente importa es si es lícito presentar la teoría kelseniana como un mero desarrollo de los puntos de vista de Austin, y sobre todo si esta presentación se basa únicamente en uno de los libros de Kelsen, la General Theory of Law and State, publicado en 1945. Creemos que Hart comete una simplificación excesiva, desconociendo la producción copiosa de Kelsen, siendo especialmente de destacar que desconoce la segunda edición de Reine Rechtslehre, que se publicó justo un año antes de su The Concept of Law, en 1960. En lugar de haber montado su crítica sobre la obra de conjunto del maestro de Viena, prefiere hacerlo sobre la teoría de Austin, un autor del siglo XIX, y de paso meter a Kelsen en el mismo «saco» teórico bajo la designación de «modelo simple». Este proceder nos parece tanto más criticable cuanto que, tras la publicación de la mencionada obra de Kelsen, tendría Hart que haber explicitado su postura respecto a esta obra. En lugar de ello, en su estudio «Kelsen's Doctrine of the Unity of Law», publicado en $1968^{20}$ maneja la primera edición de la Teoría pura del derecho, publicada en inglés en 1967, así como la edición francesa que considera «fuller and generally more accurate», publicada en 1962, desentendiéndose de la segunda edición mencionada de 1960, nada menos ocho años antes de la aparición del trabajo de Hart. Sinceramente, no acertamos a saber cómo es posible criticar, y ni siquiera entender a un autor descuidando su obra principal.

El «modelo simple» concibe el derecho -según Hart- como un conjunto de órdenes respaldadas por amenazas. Además del concepto de orden y sanción, utiliza como conceptos esenciales el de soberanía y el de hábito general de obediencia. Éstos serían los cuatro conceptos básicos del modelo simple: órdenes, amenazas, hábito general de obediencia y soberano. "Allí donde haya un sistema jurídico tiene que haber alguna persona o grupo de

${ }^{20}$ Recogido ahora en Essays in Jurisprudence and Philosophy, ya cit. pp. 309-342. 
personas que emiten órdenes generales respaldadas por amenazas que son obedecidas por lo general, y tiene que darse la creencia generalizada de que es probable que se lleven a efecto dichas amenazas en caso de desobediencia. Esa persona o grupo de personas tiene que ser supremo desde el punto de vista interno, e independiente desde el punto de vista externo. $\mathrm{Si}$-siguiendo a Austin- denominamos a esa persona o grupo de personas el soberano, las leyes de cualquier país serán las órdenes generales respaldadas por amenazas que hayan sino emitidas bien por el soberano bien por subordinados del soberano en obediencia a éste» ${ }^{21}$.

Frente a este modelo simple, Hart propone un conjunto de ideas básicas, muchas veces poco desarrolladas, que resume bajo la denominación de «modelo complejo» de teoría del derecho. El argumento de fondo es que el modelo simple es, además de simple, «simplista», por lo que es necesario sustituirlo por un modelo que matice más la complejidad de la vida de los sistemas jurídicos. Hay que señalar, no obstante, que Hart admite el «modelo simple» de teoría jurídica para explicar el derecho de las situaciones sociales primitivas, caracterizadas por su sencillez; el «modelo complejo» de teoría jurídica se adaptaría a las sociedades complejas como la nuestra.

La propuesta quizá más destacada de todas las que corresponden al «modelo complejo» es la distinción entre reglas primarias y reglas secundarias (Primary and secondary rules). En sustitución del modelo simple de «órdenes respaldadas por amenazas». Hart propone entender el derecho como «la unión de reglas primarias y secundarias» ${ }^{22}$.

El modelo simple de la teoría jurídica se caracteriza por concebir el derecho como un sistema homogéneo de órdenes o mandatos (commands) respaldados por amenazas o sanciones; para dicho modelo todo el derecho está compuesto por este género de órdenes, entendiendo por tales los mandatos que el soberano da a sus súbditos para que éstos se conduzcan de determinada manera. Ahora bien, dice Hart, «no todas las leyes ordenan al pueblo hacer o no hacer $\operatorname{cosas}\rangle^{23}$. Así, y fundamentalmente, hay leyes que lo que hacen es conferir poderes (powers, facilities), como por ejemplo las que conceden el poder para hacer testamento, para celebrar contratos o para contraer matrimonio. Junto a estas leyes que conceden poderes a los particulares (private individuals), hay aquellas que conceden poderes a los funcionarios (officials), tales como las que establecen el poder de los jueces para juzgar los casos, o de los ministros para emitir normas administrativas. Éste es el argumento principal contra el modelo simple del derecho: junto a las órdenes respaldadas por amenazas hay que admitir la existencia de otros

\footnotetext{
${ }^{21}$ Ibid. p. 25.

${ }^{22}$ Véase los capítulos III y V de The Concept of Law.

${ }^{23}$ Ibid. p. 26.
} 
tipo de reglas que no pueden ser entendidas como órdenes respaldadas por amenazas. Las órdenes o mandatos sólo pueden entenderse como expresión de la voluntad de quien manda para que el destinatario de la orden se comporte de determinada manera, bajo la amenaza de una sanción; las normas del modelo simple serían, por tanto, tan sólo normas que establecen deberes. Esta concepción es insuficiente, puesto que hay por lo menos otros tipos de normas que lo que hacen es conceder derechos o poderes, y por tanto no pueden ser entendidas en términos de órdenes respaldadas por amenazas.

La idea de la unión entre reglas primarias y secundarias constituye «la clave para entender el derecho», según la propia expresión de Hart, y un punto decisivo para distinguir el concepto de sistema jurídico (legal system) del de órdenes respaldadas por amenazas y del de moral. Tanto las órdenes respaldas por amenazas como la moral son, igual que el derecho, «medios de control social»; y aunque el derecho se relaciona con las órdenes respaldadas por amenazas y con la moral, se distingue de ellos básicamente por medio de la unión de las reglas primarias y secundarias.

Es ésta la idea más luminosa de Hart, que merece más aclaración de la que él mismo presenta. La aportación decisiva de Hart consiste en haber subrayado el carácter heterogéneo de las reglas, a diferencia de la concepción de Austin (que es la concepción imperativista que concibe el derecho como un conjunto de órdenes) y en lo esencial también de la de Kelsen, quien sostiene siempre que las normas son todas proposiciones de deber (aunque en la segunda edición de la Teoría pura introduzca los diversos operadores deónticos). Hart es más explícito que Kelsen en este punto: las normas jurídicas son heterogéneas; unas son las que establecen deberes (reglas primarias) y otras las que cumplen otras funciones distintas a establecer deberes (reglas secundarias). Hart, sin embargo, no penetra en el análisis lingüístico de las reglas y en la heterogeneidad lingüística de las mismas. Se limita a subrayar la heterogeneidad funcional de las reglas que componen el sistema jurídico. Resalta la idea de que hay dos tipos de reglas definidas por su diversa función en el sistema: las primarias, cuya función es imponer deberes, que es lo mismo que decir que exigir comportamientos; y las secundarias, cuya función no es exigir deberes sino establecer elementos distintos, que tienen en común el ser elementos en relación con las reglas primarias; por eso se dice que las reglas secundarias no son reglas de comportamiento sino reglas de las reglas, o reglas sobre las reglas primarias, para ser más exactos.

Pues bien, ni en un modelo simple de órdenes o mandatos respaldados por sanciones, ni en un sistema de normas morales, existe esa dualidad funcional de diversos tipos de reglas. En ambos medios de control social esta- 
mos ante sistemas de reglas primarias, esto es- sistemas que se reducen a un conjunto de normas que exigen deberes, prescindiendo de las reglas secundarias o reglas de las reglas. A Hart sólo le ha faltado penetrar en el análisis lingüístico de las reglas jurídicas, para verificar en qué modo el lenguaje del derecho se hace cargo de la heterogeneidad funcional de las reglas destacando su heterogeneidad lingüística, y también le ha faltado destacar el carácter institucional del derecho, como objeto de las reglas secundarias y elemento diferenciador del derecho respecto de la moral.

La ambigüedad de Hart se manifiesta de nuevo aquí. Después de haber declarado que la idea de la unión de las reglas primarias y las secundarias constituye la clave para la comprensión del derecho y de decir que tal característica «es la condición suficiente para la aplicación de la expresión "sistema jurídico"», nos mete otra vez en la incertidumbre que tanto gusta de prodigar cuando, a continuación, declara que no pretende que la palabra «derecho» tenga que ser definida en esos términos, esto es, como unión de reglas primarias y secundarias ${ }^{24}$, porque lo que él pretende no es «definir» el concepto del derecho sino «elucidarlo».

Reglas primarias son aquellas «por las que se exige a los seres humanos hacer o abstenerse de hacer determinadas acciones, tanto si lo desean como si no» ${ }^{25}$ (obsérvese que esta definición de Hart de las reglas primarias está muy próxima a la definición que critica de las órdenes respaldadas por amenazas). Junto a las reglas primarias, que constituyen el «tipo básico» de las reglas que configuran el sistema jurídico, están las reglas secundarias, que son «parásitas» (parasitic) o secundarias con respecto a las primarias, puesto que su función es hacer posible que los seres humanos «introduzcan nuevas reglas del tipo de las primarias, extingan o modifiquen reglas anteriores, determinen en diversos modos la incidencia de las reglas primarias o controlen sus efectos». La esencia de las reglas primarias es la de «imponer deberes» (duties), mientras que la de las secundarys es «conferir poderes» (powers), ya públicos, ya privados ${ }^{26}$. Deber y poder son, pues, la esencia característica de los dos tipos de reglas.

No se puede entender muy bien por qué razón niega Hart la existencia de reglas secundarias en las sociedades primitivas o de escasa evolución, en las que, según él, encaja el modelo simple de órdenes respaldadas por sanciones, lo que viene a querer decir que en dichas sociedades tan sólo existen las llamadas reglas primarias. ¿Acaso no se produce en esos contextos

\footnotetext{
${ }^{24}$ The Concept of Law, p. 208.

${ }^{25}$ Ibid. p. 78.

${ }^{26}$ Ibid. p. 79.
} 
sociales el mismo fenómeno de los poderes, tanto públicos (de la tribu o clan o comunidad) como privados (de los individuos que componen esas entidades)? Parece fuera de discusión que también en esas sociedades se crean normas y a veces se modifican (aunque el grado de modificación sea muy reducido, si lo comparamos con nuestra sociedad); también es un hecho que los individuos que forman esos grupos son titulares de una esfera de acción (diversas formas de propiedad o al menos posesión, familia, etc.,) que se traduce en un haz de poderes que les permiten llevar a efecto su vida «jurídica». Difícilmente podremos pensar la estructura jurídica de cualquier sociedad si no empleamos, al menos, las dos categorías de los deberes y los poderes; y en tal sentido, habría que afirmar que el modelo complejo de teoría no sólo es aplicable a la situación compleja de la sociedad civilizada o avanzada, sino a todas, y también por tanto a la situación simple de sociedad.

Hart introduce, como segundo carácter diferenciador entre reglas primarias y secundarias, el que se refiere a la acción o acto que contemplan. Las reglas primarias se refieren a «acciones que implican movimiento o cambios físicos», mientras que las secundarias «establecen operaciones que conducen no meramente al movimiento o cambio físico, sino a la creación o variación de deberes u obligaciones» ${ }^{27}$. Podemos decir, interpretando a Hart, que las reglas primarias son reglas de conducta o comportamiento, en el sentido de que el destinatario de las mismas está obligado a hacer algo o a dejar de hacer algo. Ese hacer o dejar de hacer es lo que quiere decir Hart cuando habla de «movimiento o cambio físico», aunque la expresión no es afortunada, porque en la abstención (dejar de hacer) precisamente lo que no hay es movimiento o cambio físico; si la regla impone un deber de abstención, lo que está imponiendo es que las cosas se queden como están, que es lo mismo que decir que el destinatario de las normas (que es el sujeto del deber de abstención) no efectúe movimiento ni cambio alguno en el medio que le rodea. El deber de no robar, que es un deber de abstención, se traduce en un deber de no realizar movimiento alguno en relación con los bienes ajenos. La caracterización que hace Hart de las reglas primarias es, por tanto, defectuosa, equivocándose al conectarlas con la realización de movimientos físicos. Más claro sería decir que las reglas primarias imponen deberes, y que éstos pueden ser tanto deberes positivos (o de realizar una acción positiva, lo cual implica la realización de movimientos físicos) como deberes negativos (o de abstenerse de realizar una acción positiva, lo cual implica no efectuar movimiento físico alguno, en relación al bien jurídico que se trata de proteger).

${ }^{27}$ Ibid. p. 79. 
En cuanto a las reglas secundarias se plantean también algunas perplejidades. Dice Hart que se caracterizan porque no implican movimiento físico, sino creación o variación de los deberes establecidos por las primarias. La regla secundaria establece un poder, y todo poder es descomponible en un haz de posibles acciones que el sujeto del poder puede realizar. Por ejemplo, si soy propietario de una casa puedo habitarla, lo cual implica un conjunto muy amplio de acciones posibles: puedo dormir en ella, puedo comer con mi familia, puedo recibir amigos, puedo ver la televisión, puedo leer, puedo escribir, etc.; además puedo venderla, hipotecarla, donarla, etc. Decir que el conjunto de poderes que me otorga el ser propietario de la casa se reduce a la «creación o modificación de deberes» no sólo es reducir mucho las cosas, sino también desenfocar exageradamente el contenido real de los poderes jurídicos. El poder que me concede la norma no sólo me permite crear deberes (ej.: vendo mi casa y de ahí surge mi deber de entregar la cosa, y el deber correspondiente de que el comprador me entregue el precio convenido). También me permite crear derechos o poderes más concretos (ej.: si vendo mi casa tengo derecho al precio, y el comprador tiene derecho a la entrega de la casa). Y tengo además poderes que también implican movimientos físicos (como son todas aquellas acciones que hemos enumerado antes y que puedo realizar en mi casa). Podemos afirmar, por consiguiente, que esta caracterización de la distinción entre reglas primarias y secundarias no está bien expuesta por Hart, sino que es excesivamente confusa.

Hart maneja otro criterio que en cierto modo es incompatible con los anteriores, aunque quizá en sí mismo considerado sea el más acertado. Según este criterio, las reglas secundarias se encuentran en un nivel diferente que las reglas primarias: las secundarias son reglas acerca (about) de las primarias. «Mientras que las reglas primarias se ocupan de las acciones que los individuos deben o no hacer», las reglas secundarias «se ocupan de las reglas primarias mismas ${ }^{28}$. Así pues, según este criterio las reglas primarias serían reglas que imponen deberes, mientras que las secundarias serían «reglas sobre las reglas» o reglas cuyo objeto no son las acciones en sí mismas consideradas, sino las reglas primarias. Obsérvese cómo este criterio es más amplio que los anteriores, y determina con mayor precisión la función de las reglas secundarias. Explícitamente dice Hart que dichas reglas «especifican los modos por los que se puede averiguar de manera concluyente cuáles son las reglas primarias, los modos en que se introducen, se eliminan y se modifican, así como los modos en que se pueden determinar de manera concluyente el hecho de su violación».

${ }^{28}$ Ibid. p. 92 
Ahora bien, ¿cuáles son las reglas secundarias? ¿cuáles son sus tipos? Hart señala tres tipos de reglas secundarias: la regla de reconocimiento (o reglas de reconocimiento, en plural), las reglas de adjudicación y las reglas de cambio.

Las reglas de cambio son aquellas que permiten la dinamicidad del sistema jurídico. Según Hart, el modelo simple de las reglas primarias es un modelo estático, ya que se reduce a ser un conjunto de reglas impositivas de obligaciones, sin que haya nada en el sistema que prevea el cambio. Un sistema complejo se caracteriza, entre otras cosas, por hacer posible la modificación de sus propias reglas, creando nuevas o variando las ya existentes. La «forma más simple» de regla de cambio es la que «faculta o dota de poder a un individuo o cuerpo de personas para introducir nuevas normas primarias... o eliminar normas viejas $\rangle^{29}$. Además de determinar las «personas que han de legislar» las reglas de cambio «pueden definir en términos más o menos rígidos el procedimiento que ha de seguirse en la legislación». Las reglas de cambio son, pues, aquellas que determinan el poder de crear o modificar reglas primarias, que además pueden establecer también el procedimiento para realizar dicha función. Gracias a ellas, el sistema jurídico puede transformarse a sí mismo. Corresponden a las categorías que Kelsen establece en la segunda edición de la «Teoría pura del derecho»: normas potestativas y normas derogatorias, que integrarían en ellas mismas el procedimiento para llevar a efecto la modificación. Siguiendo a Kelsen, Hart acepta que este concepto de reglas de cambio es aplicable no sólo a los órganos legislativos de un país, sino también a los individuos, que al celebrar contratos u otorgar testamentos, por ejemplo actúan ejercitando unos «poderes legislativos limitados» $»^{30}$.

La idea de Hart respecto de las reglas de cambio es en lo sustancial certera, aunque no esté exenta, en nuestra opinión, de graves defectos. Primero, porque no aporta una tipología suficientemente clara de las clases de reglas de cambio, englobando en ellas un conjunto muy heterogéneo de reglas (las que otorgan poderes, las que derogan otras normas, las de procedimiento). Segundo, porque no determina la naturaleza lingüística de este tipo de reglas: se limita a señalar que hay reglas cuya función es hacer cambiar las reglas primarias. Tercero, al decir que las reglas de cambio sirven para cambiar las reglas primarias (que son las impositivas de deberes) desconoce que tales reglas de cambio también sirven en todo ordenamiento jurídico para modificar las reglas secundarias; mediante reglas de cambio no sólo se cambian las reglas que imponen deberes (primarias) sino también las propias

\footnotetext{
${ }^{29}$ The Concept of Law, p. 92. y s.

${ }^{30}$ Ibid. p. 94
} 
reglas de cambio y las reglas de adjudicación, ¿cómo si no podrían variar, como de hecho varían, las propias reglas secundarias? Cuarto, no parece convincente excluir la existencia de reglas de cambio en los sistemas simples, que son aquellos en los cuales sólo existirían reglas primarias de obligación. Esta hipótesis es más una idea especulativa de Hart que una realidad, ya que no existen ordenamientos jurídicos que no cambien, aunque sin duda los hay que cambian con escasa dinamicidad. La idea de un sistema jurídico estático como correspondiente a una sociedad estática no es una visión realista del mundo del derecho.

El segundo tipo de reglas secundarias está formado por las reglas de adjudicación (rules of adjudication). "Además de identificar a los individuos que tienen que juzgar, este tipo de reglas define también el procedimiento a seguir»; «definen un grupo importante de conceptos jurídicos: los conceptos de juez o tribunal, jurisdicción y sentencia» ${ }^{31}$. Las reglas de adjudicación tienen por objeto, pues, definir los poderes y procedimientos jurisdiccionales. Si bien se mira, no hay tanta diferencia de naturaleza entre las reglas de cambio y las de adjudicación, puesto que ambos tipos consisten en la atribución de facultades o poderes y en la determinación de procedimientos.

Obsérvese que Hart utiliza reiteradamente el término «definir» para concretar la función de las reglas secundarias: las de cambio definen los poderes legislativos y sus procedimientos, mientras que las de adjudicación definen los poderes jurisdiccionales y sus procedimientos. Si tomamos al pie de la letra esa manera de expresarse, podremos decir que el derecho (en su modelo complejo) está formado por reglas primarias y definiciones; y ya que las primarias se limitan a establecer deberes, podemos simplificar más aún y decir que el derecho está compuesto por deberes y definiciones. Tal es la postura de Alchourrón y Bulygin en su estudio «Definiciones y normas».

Algunas de las críticas que hemos formulado respecto a las reglas de cambio son aplicables igualmente a las de adjudicación. Dejaremos en libertad al lector para que las encuentre a su modo y las formule libremente.

\section{La regla de reconocimiento}

A las reglas secundarias pertenece también la llamada regla de reconocimiento (rule of recognition), concepto similar al de norma fundamental en el sistema de la Escuela de Viena). El tema de la regla de reconocimiento es recurrente en la obra de Hart, y está cargado de ambigüedades y faltas de precisión ${ }^{32}$. Dada la importancia que se le ha dado en la teoría general del

${ }^{31}$ Ibid. p. 94

${ }^{32}$ Aunque recorre todo el libro, hay un capítulo de The Concept of Law especialmente dedicado al tema: el VI (Los fundamentos del sistema jurídico). 
derecho contemporánea (hasta el punto que puede afirmarse que es la tesis hartiana más conocida), vamos a detenemos un poco en su análisis.

a) La regla de reconocimiento como regla secundaria de identificación de las reglas primarias

Lo primero que salta a la vista es que Hart aborda el tratamiento de la regla de reconocimiento en el capítulo titulado «Los fundamentos del sistema jurídico». Y, nuevamente, vuelve a contraponer el modelo simple (reglas primarias) y el modelo complejo (unión de reglas primarias y secundarias). El fundamento del modelo simple radica, según Hart, «en la situación en la cual la mayoría de un grupo social obedece habitualmente las órdenes respaldadas por sanciones dadas por la persona o personas soberanas, las cuales a su vez no obedecen habitualmente a nadie $\rangle^{33}$; en el modelo de sociedad simple, por tanto, el fundamento del derecho está, en la obediencia al soberano, en la obediencia generalizada. En contraposición con el modelo simple, el modelo complejo implica que «se acepta y se usa una regla secundaria de reconocimiento para conseguir la identificación de las reglas primarias de obligación $»^{34}$. De estas afirmaciones se extraen varias consecuencias.

En primer lugar, la diferencia de naturaleza del fundamento del orden jurídico en el modelo simple y en el modelo complejo de sociedad: mientras que en el primero dicho fundamento consiste en un hecho (el hecho de la obediencia generalizada al soberano), en el segundo consiste en una regla (la regla de reconocimiento). Ello implica, además, que la regla de reconocimiento no se da en el modelo simple sino únicamente en el modelo complejo (en consonancia lógica con la idea de que en el modelo simple no se produce la dualidad de reglas primarias y secundarias). Por último, la regla de reconocimiento tiene la función primordial de reconocer o identificar las reglas primarias del sistema. Entre las reglas secundarias (que aparecen en el modelo complejo) hay una de especial importancia, cuya función consiste en identificar las reglas primarias o reglas que imponen obligaciones. En este sentido, la regla de reconocimiento puede ser denominada también regla de identificación, habida cuenta de que su función principal es la de determinar o localizar las reglas primarias de un determinado sistema jurídico. La regla de reconocimiento es la regla de identificación de las reglas primarias de un sistema jurídico complejo.

Estas ideas de Hart nos sugieren ya algunas críticas que no podemos dejar de exponer antes de seguir adelante. No parece muy coherente entender

\footnotetext{
${ }^{33}$ The Concept of Law, p. 97.

${ }^{34}$ Ibid.
} 
que el fundamento del modelo simple sea un hecho (la obediencia la soberano) mientras que el del modelo complejo sea una regla (la de reconocimiento). ¿Acaso no sería más ajustado decir que el fundamento del modelo simple está en la norma que dice que se debe obedecer las órdenes del soberano? Hart no da razón alguna que justifique la diversa naturaleza del fundamento del modelo simple y del complejo. Si el fundamento del modelo simple es un hecho, también podría ser un hecho el fundamento del modelo complejo, pues ¿acaso no se produce igualmente en este último el fenómeno de la obediencia generalizada a las reglas del sistema? Pareciera que lo que a Hart le interesa ante todo es subrayar la tesis de que en el modelo simple no hay reglas secundarias, y habida cuenta de que la regla de reconocimiento es una regla secundaria, no puede el modelo simple poseer tal regla, ¿cómo entonces podemos identificar las reglas del modelo simple si no posee una regla de identificación? Hart nos dice: observando qué reglas se obedecen. Pues bien, si esto es así podemos decir que la regla de reconocimiento del modelo simple sería la regla que dice que son reglas de tal modelo aquellas que se obedecen. Por tanto, el modelo simple también poseería su propia regla de reconocimiento, viniéndose así abajo su tesis de que sólo el modelo complejo es portador de tal regla.

b) la regla de reconocimiento como conjunto de criterios para identificar el derecho, o las fuentes del derecho

Dice Hart: «Allí donde se acepte una regla de reconocimiento, tanto las personas particulares como los funcionarios estar provistos de criterios dotados de autoridad (authoritative criteria) para identificar las reglas primarias de obligación $»^{35}$. Obsérvese, en primer lugar, la idea de que la regla de reconocimiento, para que exista como tal, ha de ser aceptada, por lo que la regla de reconocimiento precisa de un fundamento ulterior, la aceptación, que es no una regla sino un hecho. Pero dejemos este punto, sobre el cual volveremos después. Lo que nos interese resaltar ahora es la idea de que la regla de reconocimiento consiste en un conjunto de criterios en virtud de los cuales tanto los ciudadanos como los funcionarios $\mathrm{y}$, en general, todos los operadores jurídicos, pueden identificar las reglas primarias, que son, como sabemos, las reglas que imponen deberes $u$ obligaciones.

Tales criterios, nos dice Hart, pueden ser muy variados, pudiéndose presentar combinados. Se pueden identificar las reglas primarias en referencia a un texto dotado de autoridad, a la promulgación legislativa, a la práctica consuetudinaria, a declaraciones generales de determinadas personas, a decisiones judiciales... La determinación concreta de cuál sea la regla de re-

${ }^{35}$ Ibid. 
conocimiento depende del tipo de sistema jurídico que se investigue. Pero, en cualquier caso, la regla de reconocimiento consiste en un conjunto de criterios que posibilitan la identificación de las reglas primarias. Cual sea ese conjunto de criterios en concreto depender del orden jurídico en cuestión. No se puede dar una clave general para cualquier sistema, sino que los criterios en que consiste la regla de reconocimiento habrá que averiguarlos indagando de acuerdo con qué criterios funciona efectivamente el sistema.

Hart nos dice que en un sistema jurídico simple, la regla de reconocimiento consistirá en la sanción de Rex I, esto es, en el hecho de que en ese sistema es Rex I (soberano) el que promulga el derecho, no existiendo limitación alguna a su poder legislativo, y tal regla de reconocimiento se manifestar «en la práctica general por parte de los funcionarios y de las personas particulares de identificar las reglas de acuerdo con este criterio» ${ }^{36}$. Si el modelo simple de derecho se manifiesta en la existencia de una persona o grupo de personas como soberano y en la obediencia generalizada a sus órdenes respaldadas por amenazas, el criterio para identificar las reglas primarias del sistema es bien simple: todas las órdenes que emita el soberano son reglas jurídicas. Para saber cual es el derecho de un modelo semejante no habrá más que observar cuáles son efectivamente las órdenes dictadas por el soberano. Éste será el criterio identificador de las reglas primarias. Y sabremos que efectivamente es así porque los funcionarios y los particulares identifican de hecho las reglas por medio de ese criterio.

Obsérvese la contradicción de Hart. Nos acaba de decir que el modelo simple se caracteriza por no poseer reglas secundarias (y por consiguiente, tampoco regla de reconocimento), y a renglón seguido (jen la misma página!) afirma justamente lo contrario, al admitir que en el modelo simple la regla de reconocimiento viene delimitada de una manera muy sencilla. Obsérvese, además, que dice que la regla de reconocimiento es reconocida a su vez mediante la práctica general de los funcionarios y los particulares de identificar de acuerdo con el criterio mencionado cuáles son las reglas del modelo simple, lo cual quiere decir que en último término el indagador de la regla de reconocimiento ha de buscarla por medio de la observación de dicha práctica general. La regla de reconocimiento en el modelo simple remite, pues, a un hecho, al hecho de la existencia de la mencionada práctica general de funcionarios y particulares.

En un sistema jurídico complejo, la regla de reconocimiento será también más compleja, ya que en tal sistema la pluralidad de fuentes del derecho, y no sólo la sanción legislativa de Rex I. En el modelo complejo «la regla de reconocimiento es consecuentemente más compleja: los criterios

${ }^{36}$ Ibid. p. 98. 
para identificar el derecho son múltiples, incluyendo comúnmente la constitución escrita, la promulgación del poder legislativo y los precedentes judiciales ${ }^{37}$. La regla de reconocimiento de un sistema jurídico moderno incluye, por tanto, una pluralidad de criterios, los cuales no hacen otra cosa que reflejar las fuentes del derecho del sistema, que ordinariamente son la constitución, la ley y los precedentes judiciales (jurisprudencia). Éstos son los criterios que «comúnmente» configuran la regla de reconocimiento del modelo complejo, lo cual quiere decir que no siempre es así necesariamente. Por una parte, es posible que en un determinado ordenamiento falte alguno de los criterios mencionados; por otra, que existan otros además de los mencionados (como, por ejemplo, los tratados internacionales, los convenios colectivos, las normas dictadas por la administración...).

Además, en la mayoría de los casos -dice Hart- se adoptan disposiciones que permitan evitar los posibles conflictos entre los diversos criterios constitutivos de la regla de reconocimiento, ordenándolos en orden de jerarquía («ranking these criteria in an order of relative subordination and primacy»): los criterios que constituyen el contenido de la regla de reconocimiento no tienen todos el mismo nivel, sino que están ordenados jerárquicamente. Puede decirse, por consiguiente, que la regla de reconocimiento de un sistema jurídico moderno viene definida por un conjunto de criterios de ordenación jerárquica de las fuentes del derecho; lo que viene a ser lo mismo que decir que es un conjunto de criterios para ordenar jerárquicamente las normas. La regla de reconocimiento sirve entonces para identificar no sólo las reglas primarias (como dice expresamente Hart), sino también las secundarias, es decir, todas las normas que componen el orden jurídico (a excepción, claro es, de la propia regla de reconocimiento), y además de identificarlas, sirve para ordenarlas en un orden de jerarquía. De igual manera que en el supuesto del modelo simple, en el modelo complejo la existencia de la regla de reconocimiento se manifiesta o se hace perceptible a través de la práctica general de identificar las reglas jurídicas aplicando los criterios correspondientes. La práctica general de funcionarios y ciudadanos es el factor real mediante el que se averigua tanto la existencia como el contenido concreto de la regla de reconocimiento. Para saber cuál es la regla de reconocimiento de un sistema jurídico moderno o complejo es preciso acudir a la observación de dicha práctica general, con objeto de determinar cuáles son los criterios que utiliza.

Vemos, por consiguiente, que la regla de reconocimiento está condicionada, tanto en su existencia misma como en su contenido, por el hecho social de la aceptación fáctica de los criterios en cuestión, aceptación que a su

\footnotetext{
${ }^{37}$ Ibid. p. 98.
} 
vez se expresa mediante el hecho social externo de la práctica generalizada de los funcionarios y ciudadanos. Esto implica el «reconocimiento» de funcionarios y ciudadanos de la regla de reconocimiento. La regla de reconocimiento, para existir, ha de ser reconocida o acatada por operadores jurídicos y personas privadas. Podemos preguntamos entonces: si la regla de reconocimiento precisa ser reconocida a su vez mediante la observación del acatamiento que se manifiesta en la práctica general, ¿no sería más sencillo decir que un sistema jurídico está formado por aquellas reglas que acatan como tales los operadores jurídicos y los ciudadanos, y en la jerarquía en que tal acatamiento expresa? $\mathrm{Y}$ en tal caso ¿no tendríamos que decir que también en el modelo complejo y no solamente en el simple, el hábito de obediencia generalizada constituye el factor determinante de identificación de las reglas que componen el sistema?

c) la regla de reconocimiento no es una regla de derecho positivo, sino que es "mostrada» por la manera en que de hecho se identifican las reglas del sistema jurídico

Al igual que en el caso de la norma fundamental, la regla de reconocimiento no es una regla del derecho positivo. Hart dice que «muy rara vez viene formulada como una regla ${ }^{38}$, lo que sin duda quiere decir que en alguna ocasión concreta un sistema jurídico podría contener entre sus reglas una que fuera la regla de reconocimiento, pero que no tiene por qué ser necesariamente así; es más, que normalmente no es así. Además, podría suceder que el sistema jurídico determinara erróneamente su propia regla de reconocimiento; sucedería esto si tal determinación no coincidiera de hecho con la manera efectiva en que identifican las reglas del sistema los operadores jurídicos y los ciudadanos. La regla de reconocimiento viene determinada por ese modo fáctico de identificación de las reglas del sistema, y no por la declaración expresa que el propio sistema realice. No se revela como una regla «establecida» (stated) o positiva, sino como una regla «mostrada» (shown) «en la manera en que se identifican las reglas particulares por los tribunales o por otros funcionarios, o bien por las personas privadas o sus asesores». No es, pues, una regla más del sistema sino una metaregla identificadora de las reglas jurídicas positivas, que es mostrada como la descripción del modo de proceder de los operadores jurídicos.

Esta peculiar regla, que estamos analizando, tiene por tanto una naturaleza híbrida, y ello atendiendo a dos aspectos. Primero, es una regla (y por tanto un componente de todo sistema jurídico, al menos del modelo com-

${ }^{38}$ Ibid. 
plejo), pero al mismo tiempo es extrapositiva, se sitúa fuera del derecho positivo. Segundo, al tratarse de una regla tiene carácter imperativo, pero su esencia consiste en describir una práctica, la práctica identificadora de las reglas del sistema. En el primero de ambos aspectos, la regla de reconocimiento es derecho, mientras que en el segundo es un hecho. Hart es consciente de esa dualidad ambigua de la naturaleza de la regla de reconocimiento. Expresamente admite que existe una gran dificultad en clasificarla, pues escapa a las categorías convencionales ${ }^{39}$. Hart ve razones para considerar a la regla de reconocimiento tanto «derecho» como «hecho»: «El argumento para llamar "derecho" a la regla de reconocimiento es que la regla que proporciona criterios de identificación de otras reglas del sistema puede ser pensada como un rasgo definitorio del sistema jurídico y, por tanto, ser digna de llamarse "derecho"; el argumento para llamarla "hecho" es que afirmar que tal regla existe es verificar un enunciado externo del hecho real relativo a la manera en que son identificadas las reglas de un sistema "eficaz" ${ }^{40}$. Esto nos lleva a la diversa consideración desde el punto de vista interno y el punto de vista externo, de la que ya hemos hablado, pero sobre la que es preciso insistir en relación con el tema de la regla de reconocimiento.

\section{d) la regla de reconocimiento desde el punto de vista interno $y$ desde el punto de vista externo}

Ya sabemos que el punto de vista interno es el propio de quien está sometido a las reglas del sistema, mientras que el punto de vista externo es el de quien contempla el sistema desde fuera, como observador. Cuando son los ciudadanos y los operadores jurídicos sometidos a un sistema de reglas de derecho los que determinan, con su práctica habitual, el conjunto de criterios que configuran la regla de reconocimiento, estamos en presencia de ésta desde el punto de vista interno: «el uso que de las reglas (sic) de reconocimiento no expresamente formuladas hagan los tribunales y otros (sic) al identificar las reglas particulares del sistema es característico del punto de vista interno» ${ }^{41}$. Ello implica una «actitud de aceptación compartida de las reglas», que suele expresarse diciendo «el derecho dispone tal cosa», fórmula que utilizan tanto los diversos operadores jurídicos como los ciudadanos sometidos al sistema.

El punto de vista externo supone la existencia de «un observador que comprueba desde fuera (ab extra) el hecho de que el grupo social acepta dichas reglas», que él mismo no tiene por qué aceptar. Una formulación pro-

\footnotetext{
${ }^{39}$ Ibid. p. 107.

${ }^{40}$ Ibid. p. 108.

${ }^{41}$ Ibid. p. 99.
} 
pia del punto de vista externo sería por ejemplo: «en Inglaterra reconocen como derecho lo que promulga la reina en parlamento».

El punto de vista interno expresa la aceptación del grupo respecto de las reglas, aceptación que se ve ratificada por la aseveración de los miembros del grupo mismo (enunciado interno: internal statement); por su parte, el punto de vista externo supone igualmente la aceptación de las reglas por el grupo, si bien esta vez la aseveración la formula alguien que no es parte de dicho grupo (enunciado externo: external statement). Es evidente entonces que se adopte el punto de vista interno o el externo, el dato relevante es el de la aceptación de las reglas por el grupo. Tanto el punto de vista interno como el externo, y sus correspondientes enunciados, presuponen esa aceptación general. El enunciado interno es posible porque las reglas son aceptadas por el grupo con carácter general; y exactamente igual, el enunciado externo es posible por la misma razón. El centro de confluencia del punto de vista interno y del externo no es otro que la aceptación habitual o generalizada de las reglas jurídicas por parte de los integrantes del grupo. La hojarasca que cubre toda la exposición de Hart es eliminada dejando ver la verdadera naturaleza del suelo en que se apoya, que no es otro que el de un hecho sociológicamente constatable: la aceptación generalizada de las reglas del sistema. Éste es el elemento clave para determinar qué reglas componen el sistema y, en definitiva, cómo está éste configurado. Tanto el punto de vista interno como el externo dependen del hecho social de la aceptación; el interno declara la aceptación de las reglas por parte de los que las aceptan, mientras que el externo se limita a constatar el hecho social de que en general los miembros de una sociedad aceptan tales y cuales reglas como reglas de derecho.

Es esta la misma idea que ya sostuvo Bierling con su concepto de «reconocimiento» (Anerkennung), concepto que expresa el reconocimiento o aceptación social (expresa o implícita) por parte de los miembros de la sociedad, y que es el soporte necesario para la existencia de un orden jurídico válido. Idea que a su vez formularía Kelsen diciendo que para que un sistema sea válido (esto es, sea realmente un conjunto de normas jurídicas) ha de ser, en su conjunto, eficaz (puesto que la aceptación auténtica de las normas supone su cumplimiento, y por tanto la eficacia general del conjunto de las normas).

Podemos concluir este epígrafe diciendo que, en definitiva, la regla de reconocimiento expresa un hecho social, el hecho de la aceptación generalizada de las reglas de un orden jurídico. Observando tal aceptación se podrá determinar el conjunto de reglas aceptadas, que son las que configuran el sistema jurídico. Los criterios de identificación de las reglas no existen fuera de la aceptación generalizada; es ésta misma la que determina ese cri- 
terio, porque ella es el criterio. Esto explicaría la variabilidad de la regla de reconocimiento, que no consiste en otra cosa que la variabilidad de la aceptación de las reglas. Explicaría igualmente su indeterminación, pues la aceptación es un hecho social sometido a la mudanza de los tiempos. Hart hubiese sido más claro y más coherente si en lugar de inventarse el expediente de la misteriosa regla de reconocimiento, hubiera dicho pura y simplemente que la identificación de las reglas del sistema se verifica mediante la observación de las reglas que son aceptadas por los miembros de la sociedad, y que esa misma observación proporciona los criterios de jerarquía de observancia y aplicación de las reglas. Hart no ha podido liberarse del «yugo kelseniano» que su teoría lleva como una carga permanente.

\section{e) la regla de reconocimiento como determinante de la validez del resto de las reglas}

Esa indeleble impronta kelseniana que Hart lleva con cierto desagrado se hace más patente aún en cuanto vincula la regla de reconocimiento con la validez de las reglas del sistema. La regla de reconocimiento no sólo sirve para identificar las reglas, sino también para fundamentar su validez. Cumple así la misma función que la norma fundamental kelseniana. Por ello, en una ocasión el inconsciente parece traicionar a Hart y la llama «regla fundamental de reconocimiento» (basic rule of recognition) ${ }^{42}$, unificando así su propia terminología con la de su adversario ${ }^{43}$. La regla de reconocimiento no es sólo una regla identificadora de las reglas primarias del sistema, sino también la regla básica del mismo, la basic rule. Su función es, en este sentido, la de dotar de validez a las reglas jurídicas que componen el ordenamiento. Dice Hart a este respecto que «decir que una determinada regla es válida es reconocer que supera todas las pruebas establecidas por la regla de reconocimiento, y por tanto como una regla del sistema. Podemos decir sencillamente que el enunciado de que una regla concreta es válida significa que satisface todos los criterios establecidos por la regla de reconocimiento ${ }^{44}$. Una regla es válida cuando satisface todos los requisitos impuestos por la regla de reconocimiento, o, lo que viene a ser lo mismo, cuando satisface todos los requisitos impuestos por los criterios cuyo conjunto forma el contenido de la regla de reconocimiento. Dichos criterios determinan los requisitos para reconocer si una regla forma o no parte del sistema jurídico. Si la regla en cuestión satisface los requisitos exigidos por tales criterios, la regla es válida, lo que equivale a decir que pertenece al sis-

\footnotetext{
${ }^{42}$ La traducción inglesa de Grundnorm (norma fundamental) es basic rule.

${ }^{43}$ Ibid. p. 229

${ }^{44}$ Ibid. p. 100.
} 
tema jurídico, forma parte de él. En caso contrario, si no satisface los criterios exigidos por la regla de reconocimiento, la regla en cuestión no es válida, lo que quiere decir que no forma parte del sistema. Por medio de este procedimiento de comprobar en cada caso si la regla cumple o no los requisitos exigidos por la regla de reconocimiento se consigue delimitar aquellas reglas sociales que forman parte del sistema jurídico (y, por tanto, son reglas jurídicas), de aquellas otras que, a pesar de existir como reglas sociales, no pueden ser consideradas como jurídicas, habida cuenta de que no cumplen las condiciones impuestas por la regla de reconocimiento. La función identificadora que ésta cumple se complementa con su función delimitadora (del conjunto de las reglas sociales que existen en una sociedad delimita las que forman parte del orden jurídico). Las reglas que identifica la regla de reconocimiento delimitándolas de las restantes reglas sociales son las reglas válidas del sistema.

Sostiene Hart que estas operaciones, que podríamos denominar nosotros «cálculos de validez», corresponden al punto de vista interno. Pero en ello -en nuestra opinión- no lleva razón, pues nada se opone a que dicho «cálculo» sea realizado por el observador externo. Le bastará averiguar cuál es la regla de reconocimiento en un determinado sistema jurídico, para, a continuación, incluir como pertenecientes al sistema jurídico las reglas que cumplan efectivamente los requisitos requeridos por la regla de reconocimiento, excluyendo a todas las demás. Y también podrá observar cómo de hecho realizan los operadores jurídicos y los ciudadanos esa operación de inclusión/exclusión, extrayendo de ello las conclusiones pertinentes respecto de las reglas que son válidas y de las que no lo son. Por todas estas razones, es más coherente cuando afirma que la cuestión de la existencia de la regla de reconocimiento sólo puede resolverse mediante «un enunciado externo de hecho» ya que dicha existencia es «una cuestión de hecho» (a matter of fact).

\section{f) reglas de reconocimiento, validez y eficacia}

También en este tema se manifiesta la impronta kelseniana. Hart trata de la eficacia en conexión con la validez, distinguiendo, al igual que Kelsen, los dos supuestos de la regla aislada y el sistema jurídico en su conjunto ${ }^{45}$. Dice Hart que «no hay una conexión necesaria entre la validez de una regla concreta cualquiera y su eficacia, a menos que la regla de reconocimiento del sistema incluya entre sus criterios... la disposición de que ninguna regla

\footnotetext{
${ }^{45}$ Nos referimos al Kelsen anterior a la segunda edición de Reine Rechtslehere, obra publicada un año antes que The concept of Law, y que Hart no tiene en cuenta.
} 
será considerada regla del sistema cuando ya no sea eficaz desde hace tiempo» ${ }^{46}$. Habrá ocasiones en que la regla de reconocimiento establezca ese requisito, en cuyo caso la eficacia de la regla constituirá un ingrediente necesario para su validez (además de otros requisitos que tal regla deberá de cumplir, de acuerdo también con lo exigido por la regla de reconocimiento). Puesto que la regla de reconocimiento tiene un contenido variable, no siendo posible la fijación con carácter general de su contenido, habrá sistemas en los cuales dicha regla exija la eficacia como condición de validez y habrá otros en los que no. Lo más probable incluso es que haya reglas de reconocimiento que exijan ese requisito para algunas reglas del sistema, pero no para todas. La cuestión de la relación entre validez y eficacia no es susceptible, pues, de una respuesta unívoca general, sino que habrá que remitirse a la práctica generalizada del grupo para averiguar cómo funciona efectivamente ese criterio en los casos concretos de reglas particulares.

Bien miradas las cosas, el argumento de Hart es un auténtico círculo vicioso. Afirma que la regla de reconocimiento puede exigir o no exigir la eficacia como requisito de la validez de una regla. Ahora bien, como la regla de reconocimiento viene a ser la práctica generalizada de operadores y ciudadanos, para saber si una regla cualquiera es válida será preciso observar dicha práctica. La cuestión se remite, por tanto, a la práctica social, cambiante de por sí, por lo que de poco sirve tratar de teorizar el problema de la relación entre validez y eficacia. Si el grupo no acata la regla particular, es evidente que la regla no pertenece al sistema. Y viceversa, si la acata la regla es una regla válida. ¿Para qué entonces distinguir entre validez y eficacia, si la primera es, como la segunda, una mera cuestión de hecho?

La relación entre validez y eficacia, en referencia a un sistema jurídico, se resuelve en términos más claros. Para Hart, no tiene sentido hablar de validez respecto de un sistema que sea prácticamente ineficaz, que viene a ser lo mismo que decir que no existe. Podemos decir, sin embargo, que la razón es la misma que en el caso anterior: si el sistema es ineficaz lo que sucede es que la práctica general del grupo no acata las reglas, por lo que no pueden identificarse las reglas del sistema. Es la práctica generalizada de operadores y ciudadanos, nuevamente, la que proporciona el criterio último para decidir acerca de la eficacia y, por tanto, de la validez; y ello tanto respecto de la regla particular como del sistema jurídico considerado en su conjunto. Podemos concluir, por consiguiente, subrayando el relieve sociologista de este planteamiento, muestra, sin duda, de la intencionalidad de Hart de presentarnos una imagen del derecho que corresponda lo mismo a la «jurisprudencia analítica» (o teoría general del derecho) que a la «sociología descriptiva». La validez cede el paso a la eficacia (expresada mediante la práctica generalizada que la regla de reconocimiento expresa), que se

${ }^{46}$ The Concept of Law, p. 100. 
eleva así a la categoría clave. Una regla es válida (o inválida) cuando la práctica muestra que lo es; y puesto que la práctica se manifiesta a través de la eficacia (o de la ineficacia), resulta claro que es ésta última el elemento determinante en último término de la validez tanto de la regla individual como del sistema jurídico en su conjunto

\section{g) la regla de reconocimiento como regla última del sistema}

Para Hart la regla de reconocimiento es la regla última (ultimate rule) del sistema jurídico en un sentido similar a como lo es la norma fundamental de Kelsen y los «principios jurídicos últimos» (ultimate legal principles) de Salmond ${ }^{47}$. Se parece más a este último concepto en cuanto que esa regla última que es la regla de reconocimiento tiene un contenido complejo: un conjunto de criterios organizados jerárquicamente, de tal manera que uno de ellos es el «supremo». Los «criterios» hartianos juegan un papel similar a los «principios» de Salmond, a diferencia de la norma fundamental kelseniana, cuyo contenido es unívoco e invariable («se debe obedecer al poder constituyente»).

El contenido de la regla de reconocimiento es, pues, plural: está formada por un conjunto de criterios que determinan la validez jurídica de las reglas. Ahora bien, esos criterios no son todos iguales: unos son superiores y otros, subordinados. De todos ellos hay uno que es el criterio supremo. «Podemos decir que un criterio de validez jurídica o fuente del derecho es supremo cuando las reglas identificadas por referencia a dicho criterio son reconocidas como reglas del sistema incluso en el caso de que entren en conflicto con reglas identificadas por referencia a otros criterios, mientras que las reglas identificadas por referencia a estos últimos no serían reconocidas como reglas del sistema si entraran en conflicto con las reglas identificadas por referencia al criterio supremo ${ }^{48}$. Obsérvese la identificación que hace Hart entre «criterio de validez» y «fuente del derecho». Lo cual significa identificar «criterio supremo» con «suprema fuente del derecho». La regla de reconocimiento expresa los diversos criterios de validez o fuentes del derecho, pero uno de esos criterios o fuentes es el supremo, aquel que se impone a todos los demás.

La pregunta entonces surge espontáneamente: si el criterio que determina en último término la validez es el supremo, ¿por qué no admitir simplemente que dicho criterio es el que constituye el contenido de la regla de reconocimiento? ¿qué necesidad tenemos de considerar como regla de reconocimiento o regla última del sistema todo el conjunto de «criterios de va-

p. 111 .

${ }^{47}$ Salmond, Jurisprudence (1902), 12. Ed. actualizada por R.J. Fitzgerald, London 1966,

${ }^{48}$ The Concept of Law, p. 103. 
lidez» o «fuentes del derecho» que Hart nos dice? Será el criterio supremo o la fuente suprema del sistema lo que, en definitiva, determine la validez del resto de las reglas, e incluso también de los criterios restantes que configuran la regla de reconocimiento. Introducir en la regla de reconocimiento todas las fuentes del derecho como criterios identificadores de las reglas del sistema es una operación abigarrada e innecesaria, además de inconveniente, si disponemos de un nítido criterio último que determina todo lo demás. Dicho criterio último será la «fuente del derecho suprema» de la que dependerán todas las demás fuentes del derecho $\mathrm{y}$, consiguientemente, el conjunto de las reglas del sistema jurídico. Así se demuestra que no existe tanta diferencia, en este aspecto, entre la regla de reconocimiento hartiana y la norma fundamental kelseniana, puesto que la función de ambas es identificar la suprema fuente del derecho. 